\title{
Improving Project Management Practices in Architecture \& Design Offices
}

\author{
Cátia Sousa, Anabela Tereso, Gabriela Fernandes \\ Production and Systems Department / Centre ALGORITMI, University of Minho, Campus de \\ Azurém, 4804-533 Guimarães, Portugal \\ catia.m.sousa@hotmail.com, anabelat@dps.uminho.pt, g.fernandes@dps.uminho.pt
}

\begin{abstract}
This paper describes a study on improving project management (PM) practices in architecture \& design offices, conducted through semi-structured interviews and focus group with professionals from seven different offices. Taking into account the best PM practices described in literature and the most used practices and problems identified in this particular organizational context, a set of key PM practices are proposed. The results show that there are common practices already used by the architecture $\&$ design offices, such as: project charter, kick-off meeting, budgeting document and progress meetings. The problems found are mainly related to communication, collecting requirements, schedule control and portfolio management. The set of key PM practices proposed is composed by well-known practices: kick-off meeting, budgeting document, project charter, milestone planning, work packages and deadlines document, communication plan, change request, progress meeting, progress report, meeting minutes, client acceptance form and project closure documentation.
\end{abstract}

Keywords: Project management, practices, tools and techniques, architecture \& design offices.

\section{Introduction}

The market is becoming more and more competitive, which creates tremendous pressure on organizations, demanding that their projects comply with the budget, deadlines and requirements $[1,2]$. Therefore, the implementation of good project management (PM) practices to give effective and rapid response to face competitiveness is very important [3].

Although organizations are increasingly more orientated to use PM practices to manage their projects, it has not been enough, since there is still a low level of PM maturity within organizations [4]. According to International PM Association (IPMA) [5], in the last ten years PM has not undergone sufficient change to ensure success, as projects continue to fail, costing more $98.5 \%$ than the initial budget, going over the deadline by $115 \%$ and only $61 \%$ complying with the original project requirements. 
PM practices are understood in this study as the use of PM tools and techniques, which are closer to the day-to-day practice, closer to the things people do, closer to their tacit knowledge [6].

PM is context dependent $[6,7]$ i.e. we cannot expect the same results in the application of the same PM practices at all project contexts. However, PM bodies of knowledge/standards, such as the PMBoK [8], contain the best PM practices to use but do not differentiate the most appropriate for each organization context.

Understanding how to manage architecture and design projects and their particular issues appear to be limited in literature. Therefore, this study aims to identify which are the key PM tools and techniques for a particular organization context - the architecture \& design offices. Based on a set of semi-structured interviews and a focus group with elements that make up the office teams, the most used PM tools and techniques in these organizations were identified as well as their main difficulties in PM in order to come up with a set of PM practices most useful for this type of organizations.

There are architecture $\&$ design offices more focused on interior design and decoration, while others are more focused on architecture projects. Typically, interior design offices act as the intermediary between the customer and several suppliers that provide them with the products/services, such as, furniture, carpets and curtains, among others. Particularly in organizations of this typology is difficult to meet projects' requirements, deadlines and costs, because most of the products/services are subcontracted. The main work of these offices is to monitor the suppliers to ensure that the product arrives at the customer's home as expected and the installation team performs the work as agreed. These organizations have typically few employees, but they work with various subcontracted teams.

Having the first author of this paper professional experience in architecture \& design offices and having found a very low level of maturity in PM, as well as the lack of literature identifying the best practices to use in managing projects in this particular sector, this study aimed to address the following three research questions:

1. What are the PM practices commonly used in architecture \& design offices?

2. What are the major difficulties in PM in architecture \& design offices?

3. What are the key PM practices for architecture \& design offices?

The paper follows a normal structure. After the introduction, the $2^{\text {nd }}$ section makes a briefly literature review on $\mathrm{PM}$ practice. The $3^{\text {rd }}$ section describes the research methodology. The $4^{\text {th }}$ section presents the results of the most used PM practices and the main problems found in architecture \& design offices and discusses the key PM practices proposed. Finally, the main conclusions and future work are discussed.

\section{Literature Review}

The PM Body of Knowledge (PMBoK) [8] is one of the most influential publications on what constitutes the basis of the PM profession. As argued by Morris et al. [9], the more tightly defined scope in PMBoK might seem more accessible for practitioners than the 
wider range of definitions of other bodies of knowledge, such as the APMBoK, from the Association for PM [10] or the PRINCE2, that has become a standard widely used by the British government and widely recognized by the private sector being definitely the most used PM standard in the UK [11].

According to the PMBoK, PM is carried out by 47 processes organized into 5 process groups: initiation, planning, execution, monitoring and controlling, and closing.

A project consists in a value creation undertaking based on a set of objectives, which is completed in a given or agreed timeframe and under constraints, including resources and external circumstances [12].The most common projects' success criteria include time, cost and quality [13]. The ability to understand and meet customer needs also defines the quality and success of a project [14]. Customer needs can be based on quality product and appealing design, but at an acceptable cost, i.e. customers want quality at competitive prices [15]. Having technical knowledge of the product, offices may usually give the customer the desired final effect with different alternative costs, varying the material or the form of building, while keeping the product functionality.

In architecture \& design offices like in other organizations, customer requirements have to be fully interpreted to achieve positive results by the end of the project. In many situations, customers do not have technical knowledge of the product. They only have the needs they want to see fulfilled at the end of the project. Therefore, the project manager aims to plan in order to achieve the desired levels of quality and functionality within the limited cost imposed by the customer [16].

This research is based on a study conducted by Fernandes, Ward and Araújo [17] and a former study of Besner and Hobbs [18]. In 2013, Fernandes, Ward and Araújo, based on 793 questionnaires responses, identified a list of 20 of the most useful PM tools and techniques for improving project performance. Besner and Hobbs surveyed the usage of 70 tools and techniques, with 753 respondents. The tools and techniques using levels varied considerably, from 1.4 to 4.1 , based on a scale ranging from 1 (not used) to 5 (very extensive use). Fernandes et al. [17] findings were consistent with the results from Besner and Hobbs [18].

As discussed earlier, PM is context dependent [7, 19]. Each activity sector has its own characteristics, demanding a study of its peculiarities, and architecture \& design offices require PM practices tailored to their needs.

\section{Research Methodology}

The research methodology chosen for this research study was survey, based on semistructured interviews research method, as the method deemed most appropriate to perceive the real problems in this type of offices [20].

Due to time constraints and personal privileged access, the selection of organizations was restricted to Portuguese organizations. The identification of the potential companies to participate on the study was based on two criteria: their particular area of activity - 
architecture \& design, and the previous work contacts that the researcher had with some organizations.

Interviewees were elements linked to the offices' projects, namely graphic designers, designers, architects and budgeters. Organizations were contacted initially by email and later by telephone to confirm the date and time available to carry out the interviews. It was not possible to get a large number of interviews in each organization, because they are small offices, with few elements linked to projects (between five to seven team elements).

18 interviews in 7 different organizations were conducted. After the $16^{\text {th }}$ interview, the interviewer was no longer receiving new information. This means that the interviewer has nearly heard the full range of ideas and reached saturation[20], therefore it stopped the data collection process.

The interviews were conducted between May and July 2016, and were mainly face-toface interviews at the interviewee's organization headquarters (56\%), while the remaining were conducted by telephone (44\%). Before the interview, all participants received a document introducing the study and the pre-defined interview questions by email, to prepare the interviewee. Each interview started with an introduction about the respondent's background, with an outline of the research objectives and the definition of some terms used in the study, and the importance of the interviewee contribution. The interviewer asked for authorization to take notes and tape-record and assured the interviewee confidentiality and that the data obtained would only be used for academic purposes. Only $17 \%$ of respondents allowed the interview to be recorded. Each interview took on average 1 hour. The interviews were focused on exploring the main difficulties in PM in the architecture \& design offices and the PM tools and techniques used by these organizations.

Lastly, a set of key PM practices for these particular activity sector was proposed, and a focus group with participants of the interviews was conducted in order to discus and validate, in a planned way, the set of key PM practices proposed. When compared to interviews and surveys, the focus group has the advantage of easing the discussion and participation, since the answers of a participant can be complemented by others, so enriching the information obtained. This advantage was considered to largely compensate drawbacks such as the risk of someone offsetting the others [21].

\section{Results and Discussion}

\subsection{Participants' Characterization}

Respondents had a high level of academic education: $45 \%$ were Bachelors/Graduates ( 3 to 5 years of university studies), $33 \%$ were Masters and just 22\% had only a High School diploma (see figure 1). 
- Bachelor/Graduate Master High School

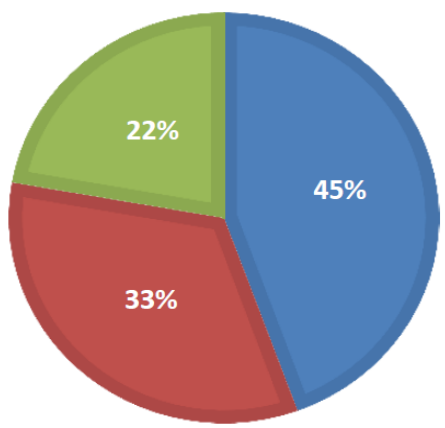

Fig. 1. Interviewees by Education Level

The participants with lower level of academic education were linked to the project's technical parts. Despite the level of academic education, they had several years of professional experience in the area. Nevertheless, none of the interviewees had any training in PM, which shows the low PM maturity level of these organizations.

The majority of participants were male (56\%). Participants from different roles in the organizations were interviewed. The respondents were linked to: Technical drawing (28\%); Architecture (22\%); Design (22\%); Project management (17\%); and Budgeting (11\%) (see figure 2).

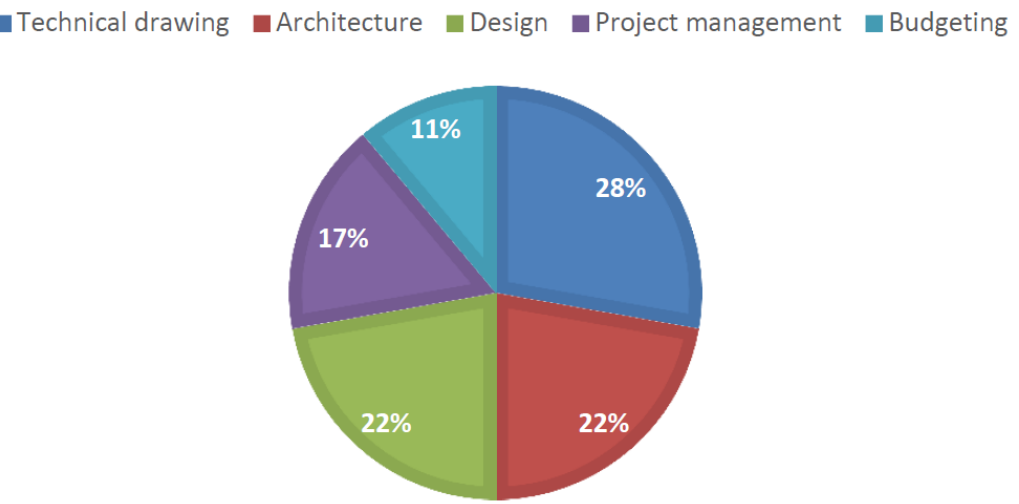

Fig. 2. Interviews by Activity Area

In this study, professionals with many years of professional experience in the area were preferred. Therefore, considering experience: $28 \%$ had over 20 years; $33 \%$ had between 
10 and 20 years; $11 \%$ had between 5 and 10 years; and only $28 \%$ had less than 5 years (see figure 3).

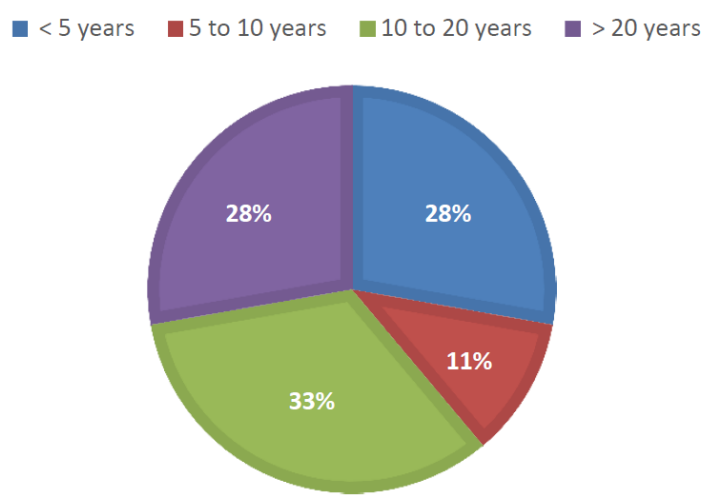

Fig. 3. Interviewees by Professional Experience

Respondents with greater professional experience helped to detect the major part of the difficulties that have occurred in these offices, as well as the PM tools and techniques used to overcome these difficulties.

\subsection{Most Used Project Management Practices in Architecture \& Design Offices}

It was found that architecture \& design offices use some of the PM tools and techniques during the project lifecycle. At the project beginning, often there is a kick-off meeting, where the project manager tries to define with the client the project's requirements and objectives.

After all requirements are identified, the architecture \& design office performs the project budget. This document is usually standardized and is delivered to the client, including project scope, time and cost. Often, it is necessary to revise the budgeting document, which includes the revision of the project requirements in order to come up with a lower cost. When the client accepts the budget and makes the order to these offices (seen as the project charter), it gives rise to the project formal beginning to carry out the project tasks. A kick-off meeting is held with the project team members, in order to share all relevant information. In some cases, at the beginning of the project, it is also held a kick-off meeting with each of the subcontractor organizations (suppliers) in order to establish all the products' requirements for to each subcontractor.

At the beginning and during the project execution, the architecture \& design offices conduct several procurement management processes to the subcontracted organizations.

During project execution several progress meetings are done, namely to approve the project deliverables with the customer and to update the project status. Telephone calls to 
the customer are also used the update project status. Communication with the internal team and external (subcontractors) teams is done through e-mails, telephone calls and presential visits. Additionally, during project execution, focus is given to control the schedule, the subcontracted work, and the execution of the entire project work.

To close the project, only few participants mentioned to have a project closure meeting. Normally the project is considered closed when the product(s)/service(s) is delivered to the customer.

Table 1 shows the PM practices most commonly used in the 7 offices, where the number of interviewees who mentioned that practice during the interviews is shown.

Table 1. Most used project management practices

\begin{tabular}{clc}
\hline Ranking & PM practices & $\mathrm{N}^{\mathrm{o}}$ interviewees \\
\hline $1^{\circ}$ & Project charter & 18 \\
$2^{\circ}$ & Kick-off meeting & 15 \\
$3^{\circ}$ & Budgeting document & 15 \\
$4^{\circ}$ & Progress meetings & 14 \\
$5^{\circ}$ & Schedule control of activities & 14 \\
$6^{\circ}$ & Control of subcontracted work & 14 \\
$7^{\circ}$ & Execution control & 13 \\
$8^{\circ}$ & Closing meeting with team members & 6 \\
$9^{\circ}$ & Preliminary studies & 5 \\
\hline
\end{tabular}

\subsection{Main Project Management Difficulties in Architecture \& Design Offices}

The interview analysis shows that there are many communication difficulties between internal team members and subcontracted organizations. Communication with outsourced organizations is hampered by the necessary supervision of the work to meet the expectations and deadlines established with the client. For architecture \& design offices to meet the deadlines, the suppliers need to deliver their product(s)/services(s) on time. The suppliers, most of the times seen as partners, should guarantee the best price and time in order to allow the offices to successfully negotiate the project with the customer.

The greatest difficulty of these offices, in terms of time, is the initial project's approval by the client. They are quite uncertain about their choices, and the more proposals they have, the more hesitant they become. Sometimes the offices end up not proposing several options just to simplify the customer's decision. After all requirements are defined, they want the project finished as quickly as possible. The projects' approval by the municipalities, on an architectural project, can take more than 6 months, which also delays the project. In this study it was not possible to define an average project duration, because all interviewees said it depends greatly on the type of project to be carried out.

Some of the projects fail to meet the deadlines established due to non-compliance by the client, sometimes because of lack of payments agreed or due to the conditions of the 
house. There are clients who hire these offices to provide the interior, but the physical spaces are not complete on time. In other cases the customer does not meet the contract regarding payments and the work is suspended until payment is done.

Although architecture \& design offices have meetings with the clients, to keep them informed of the project status, it was reported by interviewees the lack of technical elements in these meetings. Frequently there are meetings where a construction solution for a particular product is discussed with the client. This may lead to a definition that when presented to the technical elements, they realize that it is not possible to perform. This situation causes the need for a new meeting and discussion with the client.

In architecture \& design offices there is also the difficulty in prioritizing the projects because usually the offices have several projects running at the same time and need to coordinate all these projects in order to meet all project's deadlines and requirements. One of the most relevant interviewees even recognized the need to have a tool that could contain the current status of each project in progress in order to have an overview of all projects, to help in the overall portfolio management.

Some interviewees reported that there are works that, after being delivered, with all project requirements, customers complain, sometimes several months after the product(s)/service(s) is delivered by the office. The reasons for these complaints often are not responsibility of the offices, but misuse of the product by the customer.

Table 2 summarizes the difficulties encountered in these particular organizations with information about the number of people interviewed who reported each difficulty. The most often reported difficulties were communication, collect requirements and time. The difficulty in communication takes place both with internal PM members and with the subcontractors' team elements. The collect requirements present sometimes difficulties due to the customer' initial indecision, afterwards wanting the project done as soon as possible. The third problem is not being able to deliver projects on time.

\subsection{Key Project Management Practices Proposed in Architecture \& Design Offices}

After the interview data analysis, we managed to identify a set of best PM practices to architecture \& design offices, which was discussed and adjusted during the focus group (Table 3). The study focused on PM practices and excluded portfolio management practices.

The project kick-off meeting is a practice already used by these organizations. Initially they should have a meeting with the client to understand what he wants, and then a meeting with the project team members to pass information. During these kick-off meetings they should discuss all points of the project. This document accompanies the project from its initiation to its closure. 
Table 2. Project management difficulties

\begin{tabular}{lll}
\hline Ranking & Difficulties & $\mathrm{N}^{\circ}$ interviewees \\
\hline $1^{\circ}$ & Communication & 18 \\
$2^{\circ}$ & Collect requirements & 11 \\
$3^{\circ}$ & Time & 9 \\
$4^{\circ}$ & Portfolio management & 6 \\
$5^{\circ}$ & Lack of rigor in the implementation of projects & 6 \\
$6^{\circ}$ & Project closure with the client & 5 \\
$7^{\circ}$ & Project legalization & 5 \\
$8^{\circ}$ & Changes throughout the project & 4 \\
$9^{\circ}$ & Lack of information on the drawings & 4 \\
$10^{\circ}$ & Lack of rigor in the drawings & 4 \\
$11^{\circ}$ & Non-compliance with work drawings & 3 \\
$12^{\circ}$ & Lack of building conditions to start work & 3 \\
$13^{\circ}$ & Disagreement between team members & 3 \\
$14^{\circ}$ & Misreading of the drawings & 2 \\
$15^{\circ}$ & Managing the huge amount of work & 1 \\
\hline
\end{tabular}

Table 3. Set of key project management practices proposed

\begin{tabular}{l|l}
\hline Kick-off Meeting & Change request \\
Budgeting document & Progress report \\
Project charter & Meeting minutes \\
Milestone planning & Client acceptance form \\
$\begin{array}{l}\text { Document with work packages and deadlines } \\
\text { Communication plan }\end{array}$ & Project closure documentation \\
\hline
\end{tabular}

In this study, it was noted that the budgeting document sent to the client contains the product requirements to be delivered, the material, quantity, size and delivery dates. This document is essential for confirming with the customer the desired products and requirements. When the customer accepts the budget, awarding the project order, the project can start. It is used as a guarantee that the products will be delivered on the agreed date and with the requirements specified by the client.

The definition of project milestones is essential because there are several important points to fulfill during these projects. Having well-defined dates can help decreasing the delays. It was proposed that these milestones are set in the Kick-off meeting and discussed among all elements involved in the project.

Another suggestion is that these organizations should have a document with work packages and deadlines with a reference to the cost of each activity, especially in the outsourced work packages. Having values assigned to each work package can help having a more accurate budget. For the design elements, it is also very important to define who is responsible for each work package, the work to do and the deadlines to meet. 
A communication plan that follows the status of the project and its changes, to facilitate communication between project team members, should also be used. All communication between the organization and subcontracted firms should continue to be held by email, telephone and presential meetings. All design changes should also be communicated by email, with the purpose of being recorded.

Before doing changes in the project, the project manager should consult the work breakdown structure, which contains the cost for each work package, and check whether the change, if bringing additional cost, is accepted or not by the client The register of design changes aims to prevent some PM members to be left without access to information about the changes, and serves as a record to attach to the project and ultimately reflect on the consequences of adopting this change.

Progress meetings should be held quite often, especially with the customer. As suggested by the respondents, when technical aspects are discussed, the presence of technical elements is essential to support the customer. Therefore, it was proposed to include one of the elements responsible for the technical part of the project in the meetings. These meetings should be accompanied by a report (meeting minute) to register all the issues discussed and decided between the client and the team members.

In this study some of the interviewees reported that some of the projects, after delivery, suffer complaints of damaged material and several times it is due to misuse by the customer. Organizations end up suffering additional costs. A document signed by the customer to confirm the correct delivery of the material could avoid these unexpected situations, although this measure may not be well accepted, taking into account that in Portugal giving your word still has much value.

It was suggested a project closure meeting with the elements involved in the project, gathering all the necessary documents for the closure of the project or project phase. Lessons learned should be gathered and stored during the whole project life-cycle and archived during project closure. Lessons learned should not be viewed negatively but as a way to help teams to be more effective and efficient in future projects.

\section{Conclusions and Future Work}

Organizations are always looking for increase sales, reduce costs, and increase customer satisfaction. This is possible by better management of their projects, including better planning, use of resources and control.

The main contribution of this paper is to PM practice. The paper presents the most used tools and techniques in architecture \& design offices, the greatest difficulties in PM experienced by professionals in these offices and finally present a set of best practices to these organizations. 18 semi-structured interviews in 7 different architecture \& design offices were made, in order to answer the 3 research questions; and a focus group was conducted with elements from the interviews to validate the proposal set of best PM practices for architecture \& design offices. 
It was observed that these organizations have a very low PM maturity level, using few tools and techniques to overcome their difficulties throughout the project. This study had some limitations and difficulties, as it was dependent on the elements of these organizations not always willing to cooperate. The practices proposed for these architecture \& design offices were validated by the elements of the focus group, but a more comprehensive study can be done in a future work. It is suggested further in-depth studies of the benefits of using the set of practices proposed, through action research. The application of these practices in the business environment would allow to adjust the proposal of best practices presented.

Additionally, portfolio management practices should be also explored in future studies as it was identified as one of the main difficulties in this particular sector of activity.

Acknowledge: This work has been supported by COMPETE: POCI-01-0145-FEDER007043 and FCT - Fundação para a Ciência e Tecnologia within the Project Scope: UID/CEC/00319/2013.

\section{References}

1. Silvius, G., Social Project Management Strategic Integration of Social Media into Project Management Practice, IGI Global. 2016.

2. Morris, P.W.G., The Management of Projects. 1997, London: Thomas Telford.

3. Alhawari, T. Karadsheh, and Mansour, Knowledge-Based Risk Management framework for Information Technology project. International Journal of Information Management, 32(1), 50-65. 2012.

4. Silva, D., et al., OPM3® Portugal Project - Information Systems and Technologies Organizations - Outcome Analysis. New Contributions in Information Systems and Technologies, Springer International Publishing Vol. 1. 2015. 469-479.

5. IPMA. IPMA - International Project Management Association. 2012; Available from: http://ipma.ch/certification/competence/ipma-competence-baseline/.

6. Besner, C. and B. Hobbs, Project Management Practice, Generic or Contextual: A Reality Check. Project Management Journal, 2008. 39(1): p. 16-34.

7. Thomas, J. and M. Mullaly, Researching the value of project management. 14 Campus Boulevard, Newtown Square, EUA: Project Management Intitute. 2008.

8. PMI, A Guide to the Project Management Body of Knowledge (PMBOK® Guide)Fifth Edition. 2013, Newtown Square, Pennsylvania 19073-3299 USA: Project Management Institute.

9. Morris, P.W.G., et al., Exploring the role of formal bodies of knowledge in defining a profession - The case of project management. International Journal of Project Management, 2006. 24(8): p. 710-721.

10. APM, Association for Project Management. APM Body of Knowledge. 6 th edition, London, APM Books. 2012. 
11. Murray, A., et al., eds., Managing Successful Projects with PRINCE2, 5th ed., Norwich: Office of Government Commerce . 2009.

12. PMAJ, P2M - A Guidebook of Project \& Program Management for Enterprise Innovation. Project Management Association of Japan, 2005. 1.

13. Muller, R. and R. Turner, The Influence of Project Managers on Project Success Criteria and Project Success by Type of Project. European Management Journal, 2007. 25(4): p. 29-309.

14. Edwards, C.D., The Meaning of Quality. Quality Progress, 1968.

15. Broh, R.A., Managing Quality for Higher Profits: A Guide for Business Executives and Quality Managers. 1982: McGraw-Hill.

16. Dixon, D., Integrated support for project management. In: Proceedings of the 10th international conference on Software engineering. IEEE Computer Society Press. 1988.

17. Fernandes, G., S. Ward, and M. Araújo, Identifying useful project management practices: A mixed methodology approach, . International Journal of information systems and project management, 2013. 1 No.4 p. 5-21.

18. Besner, C. and B. Hobbs, The Perceived Value and Potential Contribution of Project Management Practices to Project Success Project Management Journal. Vol. 37. 2006.

19. Besner, C. and B. Hobbs, Contextualized Project Management Practice: A Cluster Analysis of Practices and Best Practices. Project Management Journal, 2013. 44(1): p. 17-34.

20. Saunders, M., P. Lewis, and A. Thornhill, Research Methods for Business Students. 5th Edition ed. 2009, Edinburgh: Pearson Education Limited

21. Langford, J. and D. McDonagh, Focus Groups: Supporting Effective Product Development. New York: Taylor \& Francis. 2003. 